\title{
Behaviour of Ti electrode in the amperometric determination of high concentrations of strong oxidising species
}

\author{
F. Terzi *, J. Pelliciari, B. Zanfrognini, L. Pigani, C. Zanardi, R. Seeber \\ Dipartimento di Scienze Chimiche e Geologiche, Università degli Studi di Modena e Reggio Emilia, Via G. Campi 183, 41125, Modena, Italy
}

\section{A R T I C L E I N F O}

\section{Article history:}

Received 22 April 2013

Received in revised form 24 May 2013

Accepted 29 May 2013

Available online 10 June 2013

\section{Keywords:}

Amperometric sensor

Titanium electrode

Hydrogen peroxide

Hypochlorite ions

Strong oxidants

\begin{abstract}
A B S T R A C T
The study of the capabilities of an unusual electrode material, namely, Ti, is presented: the amperometric determination of species showing responses that, on different materials, cannot be often profitably exploited, is proposed. $\mathrm{H}_{2} \mathrm{O}_{2}$ and $\mathrm{HClO}$ are successfully analysed, even at high concentrations. In similar conditions, which are quite common in industrial environments, these strong oxidising species are determined by time-consuming, off- or at-line, and multistep procedures. A complex real matrix, such as an industrial detergent, containing high $\mathrm{H}_{2} \mathrm{O}_{2}$ concentrations, has been taken as a meaningful study case to check the effectiveness of the electrode system and procedure proposed.
\end{abstract}

(c) 2013 Elsevier B.V. All rights reserved.

\section{Introduction}

Electroanalytical methods most commonly pay highest attention to the determination of analytes present in trace. Nonetheless, the determination of certain species at high concentrations is of particular importance in industrial and environmental contexts; dilution, however, often induces undesired or unpredictable shifts of equilibria and is obvious obstacle to in-line operations. In this respect, amperometric sensors appear appropriate to meet with both requirements, the choice of the electrode material constituting a challenging task.

Among the analytes of outmost importance in industry, strong oxidising species are commodity chemicals employed in a number of different applications, such as synthesis of inorganics and organics, treatment of drinking and waste waters and bleaching of cellulose pulp and textile [1]. As a result, strong oxidants need being determined in many different matrices over a wide concentration range, from less than $1 \mathrm{mM}$ to over $10 \% \mathrm{w} / \mathrm{w}$. However, the protocols for the quantitative evaluation of these chemicals usually require off-line or at-line procedures, such as titrations, which present obvious limitations. On the other hand, as to electroanalytical methods, the most common electrode materials, such as Pt, Au, and glassy carbon (GC), most often do not lead to repeatable and reliable amperometric responses. The main reason lies in the fouling of the electrode surface; in addition, despite the favourable thermodynamics, heavy overvoltages often affect the cathodic reduction of similar species, making the relevant responses even difficult to record. Moreover, a filtering membrane should be added to most of the electrode

\footnotetext{
* Corresponding author. Tel.: + 390592055033.

E-mail address: fabio.terzi@unimore.it (F. Terzi).
}

systems potentially suitable for similar analyses in industrial environments [2]. However, the membrane possesses limited stability over time and only allows a narrow operative temperature range; furthermore, it requires to work under critical flux conditions.

The present study is part of our researches on electrode systems different from the most usual ones, possibly suitable to give answer to analytical problems that are still unsolved. We decided to couple to organic and composite electrode systems [3], an analysis of the capabilities of metals definitely poorly common in electroanalysis. In preliminary experiments, different metals were selected on the basis of inertness, electronic properties and (electro)catalytic behaviour [4]. Ti has been rarely employed in amperometric electroanalysis [5], and in most cases, the use has been limited to low concentrations; we could not find investigations on strong oxidants at high concentrations. Our work is focused on two widely employed strong oxidising species, namely, $\mathrm{H}_{2} \mathrm{O}_{2}$ and $\mathrm{HClO}$, over a wide concentration range.

The actual nature of Ti in contact with similar species deserves a few considerations. The interaction between $\mathrm{H}_{2} \mathrm{O}_{2}$ and Ti, e.g., in the frame of corrosion processes, has been investigated by some authors [6], while literature reports dealing with the effects of other oxidising species are far from being exhaustive [7]. It has been shown that a few nanometer thick layer of $\mathrm{Ti}_{\mathrm{x}} \mathrm{O}_{\mathrm{y}}$ is spontaneously formed on Ti surface [6]. This layer consists of Ti(II), Ti(III) and Ti(IV) species and is partially amorphous in nature; the density of oxygen atoms progressively decreases with increasing the distance from the interface. It should be evidenced that the nature of crystalline $\mathrm{TiO}_{2}$ [8], widely employed as electrode material in electroanalysis, mainly under the form of particles and nanoparticles, is quite different with respect to Ti oxides spontaneously grown on $\mathrm{Ti}$, constituting the surface of our electrode. 
In addition, $\mathrm{TiO}_{2}$ electrode coatings have been often employed as a part of multicomponent materials, metal nanoparticles or enzymes being anchored to the oxide surface and representing the portion of the electrode system actually in charge of detecting the analytes [9].

Calibration curves with respect to $\mathrm{H}_{2} \mathrm{O}_{2}$ content have been drawn both in 'pure' buffered aqueous solution and in a real matrix, namely, detergent samples. Similar samples have been chosen as meaningful industrial products in which strong oxidising species are key ingredients due to their ability to remove soils. The goal of the study is hence twofold: on the one side, the potentialities of a poorly used metal electrode are studied in the frame of amperometric sensing, and on the other side, the solution to challenging analytical problems is proposed, involving (i) high concentrations of strong oxidants and (ii) effects of potentially heavily interfering species present in a complex real matrix.

\section{Experimental section}

Reagents were from Sigma. $\mathrm{H}_{2} \mathrm{O}_{2}$ was from Carlo Erba (40\% w/v). Samples of detergents have been obtained from Officina Naturae (Italy) [11]; in particular, a general purpose detergent for hard surfaces has been employed (trade name: Detersivo universale).

The electrochemical measurements were performed with an Autolab PGSTAT12 (Ecochemie) potentiostat/galvanostat, in single-compartment three-electrode cell, at room temperature. Two-millimetre-diameter Ti disks (grade 1) were the working electrodes. They were polished subsequently with $1,0.3$ and $0.05 \mu \mathrm{m}$ of alumina powder and then rinsed with Millipore water. An aqueous saturated calomel electrode, $\mathrm{KCl}$ sat. (Amel), was the reference electrode; all the potential values given are referred to it. A GC rod was the auxiliary electrode.

Solution media for the electrochemical investigations were $1 \mathrm{M}$ phosphate and citrate buffers at $\mathrm{pH} 7$ and 4 for $\mathrm{H}_{2} \mathrm{O}_{2}$ and at $\mathrm{pH} 7$ for $\mathrm{HClO} . \mathrm{pH}$ values and concentration range of $\mathrm{H}_{2} \mathrm{O}_{2}$ and $\mathrm{HClO}$ have been selected taking into account the most diffused industrial applications [1].

Voltammetric traces have been recorded starting from $0.0 \mathrm{~V}$, at 50 $\mathrm{mV} \mathrm{s}^{-1}$ potential scan rate; in correspondence to the fourth scan, a steady-state was reached, and the response could be used for analytical purposes. Random additions have been employed for the construction of the calibration curves. Regression of the experimental data is most satisfactory when using a second-order polynomial. Sensitivity is computed as the first derivative of the calibration function calculated in correspondence of the midrange value [11]. All experiments have been carried out in solutions in equilibrium with the atmosphere, i.e., in the
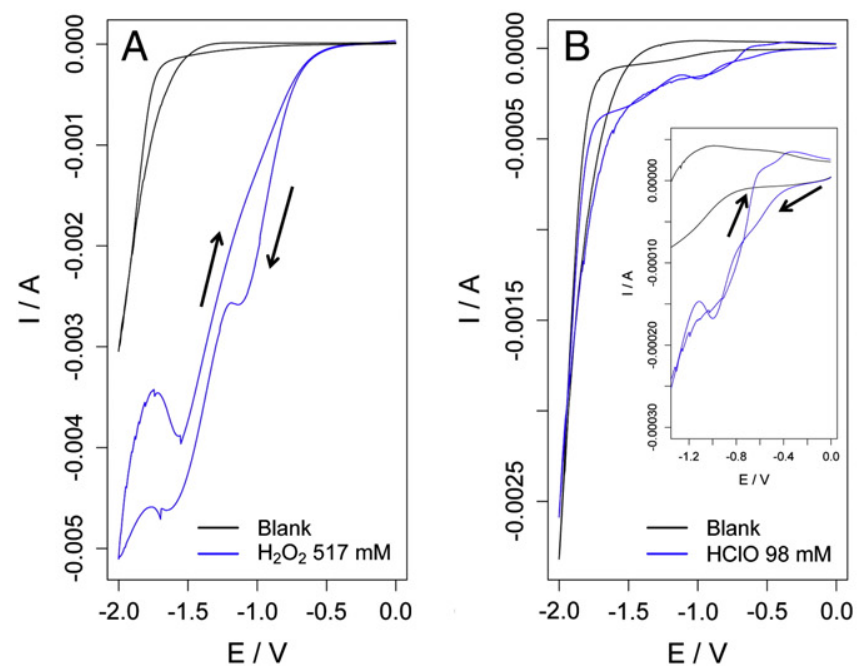

presence of dissolved oxygen, to mimic the conditions typical of applicative contexts. However, we could check that the removal of oxygen through deaeration with nitrogen does not lead to significant variation of the electrochemical responses. Lack of sensitivity of Ti electrodes to oxygen reduction, which represents one of the heaviest potentially interfering species, constitutes a further advantage of such a metal electrode.

$\mathrm{H}_{2} \mathrm{O}_{2}$ concentration, both in buffered and in detergent samples, has been determined through standard titration procedure, namely, ASTM D2180 test.

\section{Results and discussion}

The voltammetric responses of the Ti electrode relative to cathodic reduction of $\mathrm{H}_{2} \mathrm{O}_{2}(514 \mathrm{mM})$ and $\mathrm{HClO}(98 \mathrm{mM})$ are reported in Fig. $1 \mathrm{~A}-\mathrm{C}$, respectively. These values represent the highest concentrations explored since the solution $\mathrm{pH}$ is not faithfully buffered above them. In the case of $\mathrm{H}_{2} \mathrm{O}_{2}$, two current peaks, located at ca. -1.1 and $-1.6 \mathrm{~V}$, are evident in the forward potential scan at $\mathrm{pH} 7$; at $\mathrm{pH} 4$ they are shifted toward less negative values and that with $\mathrm{Ep} \simeq-1.0 \mathrm{~V}$ appears as a shoulder. In the case of $\mathrm{HClO}$, only one peak $(\mathrm{Ep} \simeq-1.0 \mathrm{~V}$ ) is present at $\mathrm{pH} 7$.

Miah et al. [12] ascribes the two peaks in the forward scan on $\mathrm{H}_{2} \mathrm{O}_{2}$ solutions to the reduction of the analyte and of oxygen species formed as a consequence of its catalytic decomposition and adsorbed on the electrode surface. The current in the backward scan exhibits an odd behaviour: though smaller with respect to the forward scan, cathodic currents are still observed. Actually, the reduction mechanisms of similar species is quite complex and far from being exhaustively clarified, even on noble metal electrodes. Similar behaviour has been previously reported in the case of noble metals in aqueous solvents [13]. Burke et al. [14] proposed a model based on the formation of metal hydrous oxide species on the electrode in correspondence to positive and even slightly negative potentials. These species still survive at surprisingly negative values, giving rise to surface phenomena far from being clear, also leading to persistent cathodic currents.

Sharp current oscillations are evident, past the first portion of the signal, in the voltammetric traces in Fig. $1 \mathrm{~A}-\mathrm{C}$ : the formation of $\mathrm{O}_{2}$ small bubbles at the electrode are visible, which accounts for the oscillations observed.

We could check that Pt and GC electrodes cannot be fruitfully employed in the determination of $\mathrm{H}_{2} \mathrm{O}_{2}$ [13]; in addition, Au could not be employed in the real matrices used in the present communication due to strong fouling of the surface. On the other hand, the
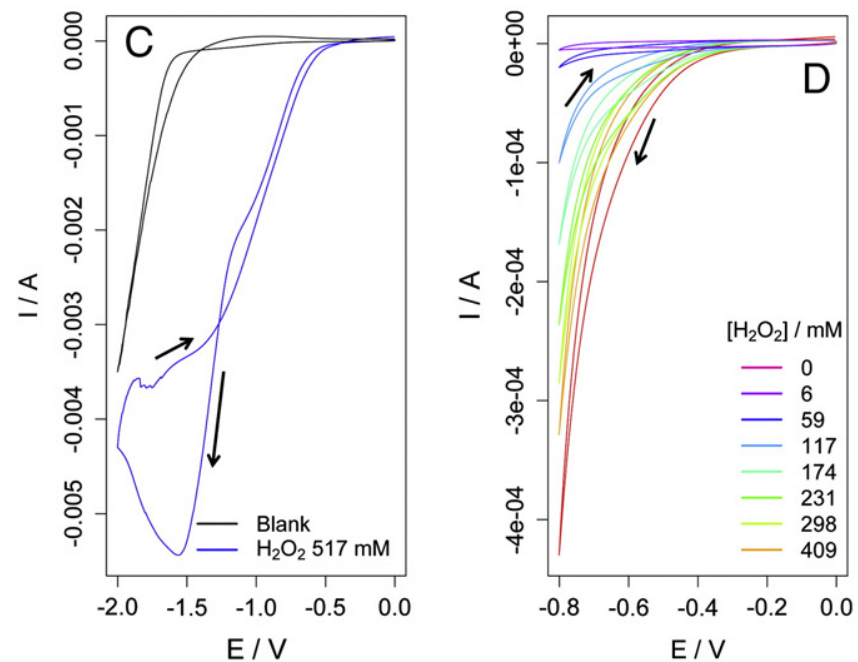

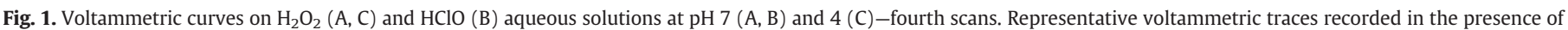
different $\mathrm{H}_{2} \mathrm{O}_{2}$ concentrations at $\mathrm{pH}$ 7-fourth scans (D). 

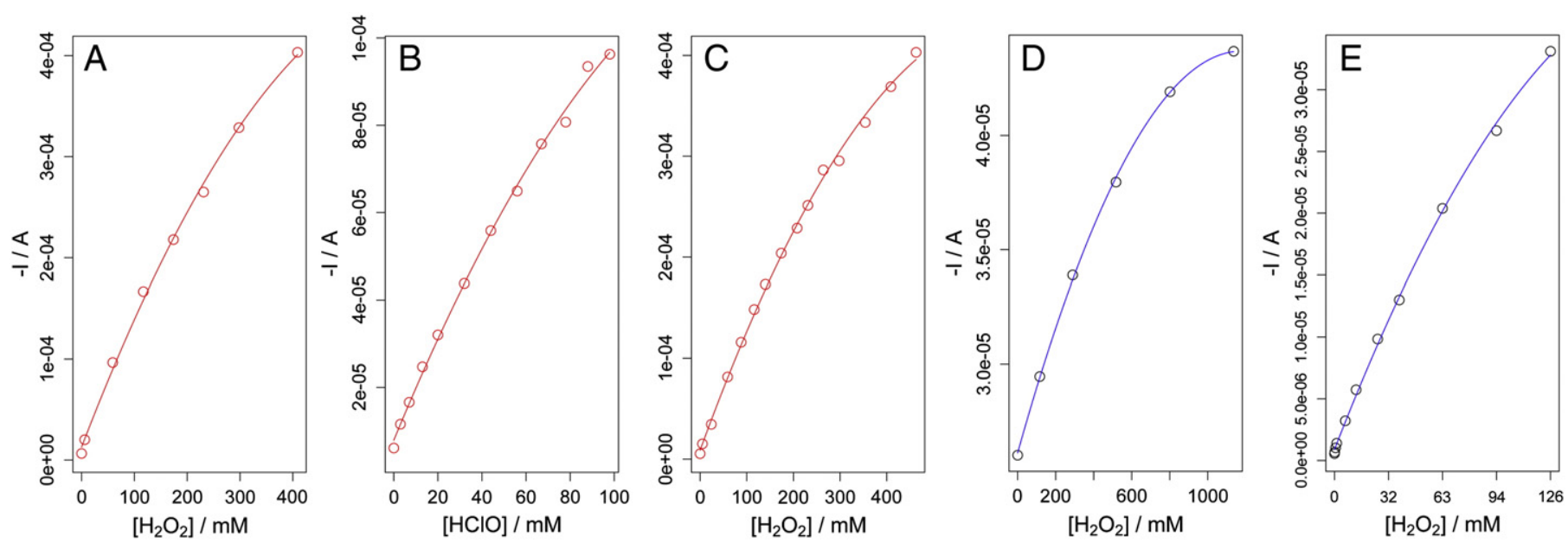

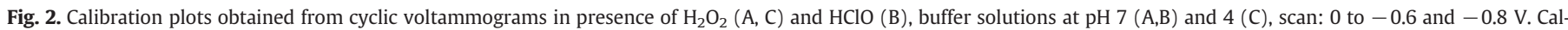

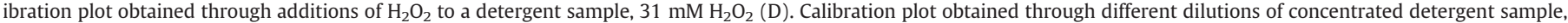
$126 \mathrm{mM} \mathrm{H}_{2} \mathrm{O}_{2}$ (E).

analytical performance of the Ti electrodes in the determination of $\mathrm{H}_{2} \mathrm{O}_{2}$ and $\mathrm{HClO}$ by cathodic reduction has been evaluated through calibration procedures. The relevant plots have been constructed by recording voltammetric curves from $0.0 \mathrm{~V}$ over a wide potential range at $\mathrm{pH} 4$ and 7 , finally choosing the current values at the $-0.8 \mathrm{~V}$ (Fig. 1D). This potential has been adopted because it represents the best compromise between sensitivity and reproducibility: the sensitivity decreases at decreasing the polarisation potential (e.g. 0.09, 0.54 and $1.30 \times 10^{-6} \mathrm{~A} \mathrm{mM}^{-1}$ for $\mathrm{H}_{2} \mathrm{O}_{2}, \mathrm{pH} 7$, at $-0.6,-0.8$ and $-0.9 \mathrm{~V}$, respectively), and the confidence interval of the prediction in correspondence of midrange concentration [10] is significantly higher in the case of -0.6 and $-0.9 \mathrm{~V}$ (e.g. 44, 16, $30 \mathrm{mM}$ for $\mathrm{H}_{2} \mathrm{O}_{2}$, $\mathrm{pH} \mathrm{7,} \mathrm{at}-0.6,-0.8$ and $-0.9 \mathrm{~V}$, respectively), which reflects the higher extent of the random errors. In addition, it has been ascertained by us that best reproducibility between different sets of measurements also requires that the polished $\mathrm{Ti}$ electrode is pre-conditioned by cycling the potential from 0.0 to $-0.8 \mathrm{~V}$ (50 scans, $50 \mathrm{mV} \mathrm{s}^{-1}$ scan rate) in the presence of the maximum $\mathrm{H}_{2} \mathrm{O}_{2}$ or $\mathrm{HClO}$ concentration explored.

Noteworthy, the plot of the current vs. concentration is fitted at best by a parabolic curve (Fig. $2 \mathrm{~A}-\mathrm{C}$ ). The acknowledged complexity of the underlying cathodic mechanism forced us to conclude that a possible explanation to this behaviour is merely speculative. The upper concentration limit for the calibration curves is imposed by the increasing scattering of the data. This behaviour is plausible, due to lack of $\mathrm{pH}$ control in presence of complex $\mathrm{pH}$ dependent mechanisms.
In absence of a law supporting the fitting function, as a support to the reliability of the trend obtained, we tested three calibration plots under similar experimental conditions. The electrode systems and the relevant responses resulted also fairly reproducible, as deduced, by the application of $t$-tests, by the lack of significant differences between the calibration plots obtained with three different electrodes on the highest and lowest sensitivity values and the relevant standard deviations $(p>95 \%)[10]$.

The system and experimental conditions were not specifically developed for the determination of particularly low $\mathrm{H}_{2} \mathrm{O}_{2}$ or $\mathrm{HClO}$ concentrations. However, calibration plots over a range of low concentrations, much narrower with respect to the previous case (0-20 $\mathrm{mM}$ for $\mathrm{H}_{2} \mathrm{O}_{2}$ and $0-5 \mathrm{mM}$ for $\mathrm{HClO}$ ), have been drawn to estimate the potentiality of the system in similar situations. The results (Table 1) show that the limit of detection (LOD), computed on the calibration plot over a low concentration range [10], is below ca. $2 \mathrm{mM}$ for both species at the different $\mathrm{pH}$ values (Table 1 ). By computing LOD as three times the standard deviation of the blank signal, as it is common practice in the literature, it results of ca. $0.01 \mathrm{mM}$.

As a sound example of the antifouling properties of Ti electrode material, the $\mathrm{H}_{2} \mathrm{O}_{2}$ content in detergent samples was determined. The formulation of detergents is particularly complex: a number of species potentially leading to adsorptions poisoning the electrode surface, such as surfactants, builders, and hardness control agents, are present [15]. In our case, the formulation consists of cocoglucosides and cocamidopropyl betaines $(4 \% \mathrm{w} / \mathrm{w})$ and ethanol $(8 \% \mathrm{v} / \mathrm{v})$ in

Table 1

Second-order calibration for $\mathrm{H}_{2} \mathrm{O}_{2}$ and $\mathrm{HClO}$ at different pH. Regression equation: $i=\mathrm{Ac}^{2}+\mathrm{Bc}+\mathrm{D}$.

\begin{tabular}{|c|c|c|c|c|c|c|c|c|c|}
\hline Analyte & Concentration range $(\mathrm{mM})$ & $A\left(\times 10^{10}\right)^{c}$ & $B\left(\times 10^{6}\right)^{c}$ & $\mathrm{D}\left(\times 10^{6}\right)^{\mathrm{c}}$ & $S^{d}$ & $s^{e}$ & $\mathrm{Cl}^{\mathrm{f}}$ & $n^{g}$ & LOD $(\mathrm{mM})^{\mathrm{h}}$ \\
\hline \multirow[t]{2}{*}{$\mathrm{H}_{2} \mathrm{O}_{2}$, pH 7} & $0 \div 400$ & $10(1)$ & $-1.36(0.06)$ & $-13(4)$ & 0.54 & 3 & 16 & 24 & \\
\hline & $0 \div 20$ & $-110(18)$ & $-3.8(0.3)$ & $-6.9(0.1)$ & 4.18 & 5 & 1 & 27 & $1.1[0.01]$ \\
\hline \multirow[t]{2}{*}{$\mathrm{HClO}, \mathrm{pH} 7$} & $0 \div 100$ & $32(6)$ & $-1.22(0.06)$ & $-8(1)$ & 0.59 & 3 & 4 & 36 & \\
\hline & $0 \div 5$ & $460(50)$ & $-2.1(0.03)$ & $-5.1(0.3)$ & 1.61 & 8 & 1 & 18 & $0.4[0.04]$ \\
\hline \multirow[t]{2}{*}{$\mathrm{H}_{2} \mathrm{O}_{2}, \mathrm{pH} 4$} & $0 \div 460$ & $9.4(0.7)$ & $-1.27(0.03)$ & $-9(3)$ & 0.40 & 3 & 13 & 45 & \\
\hline & $0 \div 20$ & $81(5)$ & $-1.50(0.09)$ & $-5.9(0.3)$ & 1.16 & 4 & 1 & 27 & $0.7[0.05]$ \\
\hline Detergent sample ${ }^{a}$ & $31-1100$ & $0.127(0.006)$ & $-0.0298(0.0007)$ & $-26.1(0.1)$ & 0.015 & 1 & 25 & 11 & \\
\hline Detergent sample & $0.013-126$ & $8.3(0.8)$ & $-0.36(0.01)$ & $-0.9(0.2)$ & 0.25 & 2 & 3 & 11 & \\
\hline
\end{tabular}

a Calibration plot obtained through additions of $\mathrm{H}_{2} \mathrm{O}_{2}$ to a detergent sample containing $31 \mathrm{mM} \mathrm{H}_{2} \mathrm{O}_{2}$.

b Calibration plot obtained through different dilution levels of a concentrated detergent sample (126 $\mathrm{mM})$.

c Standard deviation of the coefficients are reported in parentheses.

d $\mathrm{S}$ : sensitivity $\left(\times 10^{6} \mathrm{~A} / \mathrm{mM}\right)$.

e s: the process standard deviation ( $\mathrm{s}$ in \%).

${ }^{\mathrm{f}} \mathrm{Cl}$ : confidence interval of the prediction in correspondence of midrange concentration value ( $\mathrm{mM}, p=95 \%$ ).

$\mathrm{g} n$ : number of concentration values used for the construction of the calibration plot.

$\mathrm{h}$ LOD computed on the calibration plot over a low concentration range and, within squared brackets, as three times the standard deviation of the blank signal. 
aqueous solvent. It is worth noticing that it is not possible to remove $\mathrm{H}_{2} \mathrm{O}_{2}$ from the matrix, without altering its composition, due to the presence of volatile compounds. A conventional calibration, consisting of addition of different, known amounts of $\mathrm{H}_{2} \mathrm{O}_{2}$ to the background, is hence impractical. That's why the starting solution consisted of a detergent sample containing $31.0 \mathrm{mM} \mathrm{H} \mathrm{H}_{2}$ and has been obtained by dilution of the pure detergent solution, with demineralised water ( $10 \mathrm{ml}, \mathrm{pH}$ 5.3). The $\mathrm{H}_{2} \mathrm{O}_{2}$ concentration in this solution was computed by titration, according to the cited standard procedure; then, calibration plots have been constructed adding known aliquots of standard $\mathrm{H}_{2} \mathrm{O}_{2}$ solution ( $40 \% \mathrm{w} / \mathrm{v}$ ), dissolved in so small volumes ( $50 \mu \mathrm{l}$ each) not to alter the composition of the solution. Repeated tests led to well-reproducible calibration curves in a concentration range from $31 \mathrm{mM}$ to $1 \mathrm{M}$ (Fig. 2D), employing a parabolic regression equation. When applied for the determination of an unknown sample, the $\mathrm{H}_{2} \mathrm{O}_{2}$ concentration can be determined with good accuracy $(p>95 \%)$.

In particular, the specific case of detergents requires that the solutions for the different applications are obtained by suitable dilution of the commercial product [10]. Following such a procedure, an $\mathrm{H}_{2} \mathrm{O}_{2}$ concentration range from ca. 126 to $0.013 \mathrm{mM}$ was explored. A second-order function still results to regress at best the experimental points (Fig. 2E). Repeatability and reproducibility were also characteristic of these tests, demonstrating that the analytical determination is possible in-line, at any stages of the detergent production and use.

\section{Conclusions}

The present work demonstrates that a Ti electrode can be effectively employed for the determination of strong oxidising species over a wide concentration range. It operates successfully even at particularly high values, which are usually quite critical. In particular, $\mathrm{H}_{2} \mathrm{O}_{2}$ and $\mathrm{HClO}$ can be cathodically reduced, leading to repeatable and reproducible voltammetric traces. Ti electrodes also proved to be resistant to fouling species such as those present in detergent formulations, so that the quantitative evaluation of $\mathrm{H}_{2} \mathrm{O}_{2}$ in a real very complex matrix results very satisfactory.

\section{References}

[1] C.W. Jones, Applications of Hydrogen Peroxide and Derivatives, RSC Publishing, London, 1999

[2] Patent WO/2001/013103.

[3] C. Zanardi, F. Terzi, R. Seeber, Analytical and Bioanalytical Chemistry 405 (2013) 509.

[4] J. Zhang, PEM Fuel Cell Electrocatalysts and Catalyst Layers, Springer-Verlag, Berlin, 2008.

[5] C.M. Ronconi, P.R. Zanotto, U. Brocksom, P.A.P. Nascente, E.C. Pereira, Journal of Applied Electrochemistry 34 (2004) 1229.

[6] X. Liu, P.K. Chu, C. Ding, Materials Science and Engineering R 47 (2004) 49.

[7] L.B. Golden, R. Lane, W.L. Acherman, Industrial and Engineering Chemistry 44 (1952) 1930.

[8] X. Chen, S.S. Mao, Chemical Reviews 107 (2007) 2891.

[9] P. Xiao, Y. Zhang, B. Batalla Garcia, S. Sepehri, D. Liu, G. Cao, Journal of Nanoscience and Nanotechnology 9 (2009) 2426.

[10] Officina Naturae, http://www.officinanaturae.com.

[11] In: M. Reichenbacher, J.W. Einax (Eds.), Challenges in Analytical Quality Assurance, Springer, Heidelberg, 2011.

[12] M.R. Miah, T. Ohsaka, Analytical Chemistry 78 (2006) 1200.

[13] F. Terzi, J. Pelliciari, C. Zanardi, L. Pigani, A. Viinikanoja, J. Lukkari, R. Seeber, Analytical and Bioanalytical Chemistry 405 (2013) 3579.

[14] L.D. Burke, Gold Bulletin 37 (2004) 125.

[15] In: K.-Y. Lai (Ed.), Liquid detergent, Second ed., CRC Press, Boca Raton, 2005. 